\title{
CAUSAS DE LA RELATIVA FACILIDAD DE LA CONQUISTA DEL PODER POR STALIN DESPUÉS DE LA REVOLUCIÓN DE OCTUBRE
}

H. C. F. Mansilla*

RESUMEN: La toma del poder por José Stalin y la edificación de un régimen totalitario en la Santa Rusia muy poco tiempo después de la Revolución de Octubre (1917) fueron posibles porque casi todos los dirigentes bolcheviques y hasta los grupos opositores a Lenin y Stalin dentro del partido comunista compartían un idéntico desprecio por el pluralismo democrático y el Estado de derecho. Esta ceguera con respecto a valores culturales y normas colectivas de orientación era asimismo característica de numerosos intelectuales progresistas en Europa occidental, como Rosa Luxemburgo, y de personalidades del Partido Comunista que se opusieron a Stalin en un principio.

PALABRAS ClaVE: Rosa Luxemburg, Trotsky, Lenin, régimen totalitario.

\section{Causes of the Relative Ease}

OF STALIN'S CONQUEST OF POWER AFTER THE

OCTOBER REVOLUTION

ABSTRACT: The seizure of power by Joseph Stalin and the building of a totalitarian regime in Holy Russia very soon after the October Revolution (1917) were possible because nearly all the Bolshevik leaders and even opposition groups to Lenin and Stalin in the Communist Party shared an identical contempt for democratic pluralism and the rule of law. This blindness to cultural values and collective rules of guidance was also characteristic of many progressive intellectuals in Western Europe, such as Rosa Luxemburg, and personalities of the Communist Party who opposed Stalin at first.

KeYwords: Rosa Luxemburg, Trotsky, Lenin, totalitarian regime.

* Academia de Ciencias de Bolivia y miembro de la Real Academia Española. 


\section{CAUSAS DE LA RELATIVA FACILIDAD DE LA CONQUISTA DEL PODER POR STALIN DESPUÉS DE LA REVOLUCIÓN DE OCTUBRE}

\section{Desde un comienzo}

\section{Rosa Luxemburgo (1871-1919) fue} una de las exponentes más notables de un marxismo independiente y, por ello, un caso muy interesante para observar la tesis de un amplio rechazo a la democracia pluralista y de un aprecio concomitante del dogmatismo marxista. Ya en 1904 había censurado el "ultracentralismo brutal" contenido en la nueva concepción del partido de Lenin: el intento de introducir la disciplina del cuartel, la fábrica y de los estamentos burocráticos en el partido socialdemócrata, lo que había dado como resultado una élite dirigente privilegiada y una masa de seguidores sometidos a la obediencia más estricta y separados para siempre de la cúpula decisoria. Como se sabe, Luxemburgo mantuvo su posición crítica del partido bolchevique después de la Revolución de Octubre de 1917. ${ }^{1}$ Ahora bien, al mismo tiempo sostuvo como verdades indubitables algunos teoremas importantes del marxismo que ya entonces eran muy controvertidos: la validez intangible de todos los pronósticos de Marx sobre el desarrollo de la economía capitalista, la polarización ince-

${ }^{1}$ Rosa Luxemburgo, “Organisationsfragen der russischen Sozialdemokratie" [1904], en Susanne Hillmann (comp.), Schriften zur Theorie der Spontaneität, 1971, Reinbek, Rowohlt, pp. 71, 74-80. Cfr. sus observaciones ejemplarmente críticas acerca de la dictadura del partido bolchevique (heredero de las estrategias conspirativas de los jacobinos) en su obra póstuma "Die russische Revolution", en ibid., pp. $171,188$. 
sante de clases, la pauperización creciente del proletariado, la necesidad de subordinar las labores sindicales a las políticas, la inutilidad de toda labor parlamentaria (el sistema parlamentario como "cretinismo"), el carácter meramente "formal" de la burocracia "burguesa" (contrapuesto a la verdadera democracia socialista) y la obligación de impedir todo "reformismo pequeño burgués". ${ }^{2}$ Por otra parte, Rosa Luxemburgo insistía en el tema marxista de rechazar y combatir la organización federal del Estado, los particularismos regionales y las peculiaridades históricas preburguesas y preindustriales en cuanto reliquias singularmente odiosas del régimen "feudal". El centralismo estatal de corte unitario constituiría uno de los grandes logros del capitalismo, que la revolución socialista debería profundizar a toda costa y que sería especialmente adecuado para países con varias nacionalidades, como Rusia. Rosa Luxemburgo se opuso tenazmente a la independencia de su patria, Polonia.

También León Trotski (1879-1940) criticó acremente en 1904 la concepción leninista del partido, posición de

${ }^{2}$ Rosa Luxemburgo, Die russische, p. 191. Sobre la obra de Rosa Luxemburgo, véase. F. L. Carsten, "Freiheit und Revolution: Rosa Luxemburg", en Leopold Labedz (comp.), Der Revisionismus, 1966, Colonia, Berlín, Kiepenheuer und Witsch, pp. 68-95, especialmente pp. 78-81. la cual abjuró en definitiva en 1917, cuando se plegó a la doctrina leninista en cuestiones de organización y cuando Lenin se adhirió, en lo esencial, a su teoría de la revolución permanente. ${ }^{3}$ De modo clarividente, Trotski previó que el modelo leninista produciría efectos imprevistos: la élite de revolucionarios profesionales tomaría a su cargo la labor de "dirigir y educar" al proletariado, que quedaría reducido a obedecer. El partido sustituiría la voluntad del proletariado, el comité central la del partido y el "dictador" la del comité central. ${ }^{4}$ Después de renunciar a este enfoque crítico, Trotski se convirtió - o volvió a ser- un apologista de los temas

${ }^{3}$ Trotski, Die permanente Revolution, 1971, Fráncfort, EVA, pp. 24-25, 62-63, 112, 123. En esta obra, Trotski sistematizó su concepción, que sería particularmente popular en las periferias europeas, en tierras del Tercer Mundo y entre revolucionarios profesionales: la revolución socialista brotaría de modo más probable en aquellas sociedades subdesarrolladas que denotaran una mayor madurez político-ideológica que en las naciones económicamente más avanzadas. La "revolución democrático-burguesa" tendría lugar junto con la socialista y en un lapso extremadamente breve. Aunque el triunfo definitivo de una revolución socialista estuviera ligado — según Trotski — a su expansión a las sociedades más industrializadas, el lugar para el estallido revolucionario se trasladó a comunidades históricamente menos evolucionadas y se potenció el factor subjetivo, es decir, la función central y dirigente de la élite de revolucionarios intelectuales.

${ }^{4}$ Trotski, "Unsere politischen Aufgaben" [1904], en Hartmut Mehringer (comp.), Schriften zur revolutionären Organisation, 1970, Reinbek, Rowohlt, pp. 68, 73 (teorema de la sustitución de voluntades políticas). 
más reaccionarios y de los métodos más duros del régimen soviético. Con toda razón se le ha llamado un precursor del estalinismo. ${ }^{5}$

\section{Los opositores a Stalin}

Trotski, el creador del Ejército Rojo, fue un genio de la organización y la estrategia militares; pero, en su calidad de Comisario del Pueblo para el Ejército y la Marina y Presidente del Soviet Supremo Militar, ordenó el 8 de agosto de 1918 el establecimiento de "campos de concentración" no solo para "saboteadores y oficiales contrarrevolucionarios", sino para los "parásitos sociales" y todo aquel opositor que saliese con vida de un juicio militar sumario. ${ }^{6}$ Esta actitud se inscribe en su vehemente rechazo a toda manifestación de rebeldía e insubor-

${ }^{5}$ El título de un libro de Willy Huhn es tan preciso como lacónico: Trotzki-der gescheiterte Stalin ("Trotski: el Stalin fracasado"), 1971, Berlín, Kramer, especialmente el capítulo "Trotzki und die proletarische Revolution", pp. 23-73. Para otras críticas a Trotski, véase N. Osinski [Valerian V. Obolenski], Zur Frage der "Militarisierung der Wirtschaft" [1920], en Frits Kool y Erwin Oberländer (comps.), Arbeiterdemokratie oder Parteidiktatur, 1967, Olten/Friburgo, Walter, pp. 141-157; Robert Vincent Daniels, The conscience of the revolution. Communist opposition in Soviet Russia, 1965, Cambridge, Harvard University Press, pp. 104, 108-109, 121-124, 194, 224, 231, 240 (la obra más destacada y mejor documentada sobre este tema).

${ }^{6}$ Willy Huhn, Trotzki, pp. 38-39. Es una de las primeras menciones al concepto de "campo de concentración". dinación contra sus ideas y órdenes, aunque sea solo en el campo intelectual. La historia posterior del trotskismo y de la IV Internacional — una historia de mezquindades ridículas y escisiones pintorescas, que no aportó nada al florecimiento de un marxismo crítico - tiene que ver probablemente con ese espíritu de intolerancia y sectarismo, por demás cercano a las tradiciones rusas y asiáticas más habituales de su tiempo. En este sentido, no es de extrañar que Trotski haya defendido la utilización de cualesquiera medios para alcanzar determinados fines, con el argumento de que ello ha sido lo corriente a lo largo de la historia universal. ${ }^{7}$ Aparte de celebrar la función progresista de la violencia política, Trotski compartió la difundida opinión de que los derechos humanos, la democracia representativa y el pluralismo ideológico constituirían meras formalidades con utilidad instrumental. ${ }^{8}$ Contra las fracciones de izquierda dentro del partido bolchevique y basado en la idea muy convencional de que el hombre es perezoso por naturaleza, en 1920 Trotski propuso (con cierto éxito) la militarización de las relaciones laborales y

${ }^{7}$ Trotski, Terrorisme et communisme. L'AntiKautsky, 1963, París, Union Générale d'Editions, p. 28 y caps. II-III. En 1935 mantuvo esta posición, afirmando que la violencia es la ley histórica del progreso: Trotski, Préface à la deuxième édition anglaise, pp. 314-315.

${ }^{8}$ Ibid., pp. 57-83, 99-107, 315. 
de los sindicatos para conseguir la disciplina, el sacrificio y el sentido de jerarquías que solo se da en el ejército, apoyado en este punto por su famoso adversario Nikolai I. Bujarín (18881938), que después de Lenin era el teórico más destacado del partido. ${ }^{9}$

En el exilio y tras experimentar en carne propia los rigores de pertenecer a la oposición, numerosos líderes comunistas, entre ellos Trotski, descubrieron y reconocieron tibiamente las bondades de la legalidad y la democracia burguesas, pero sin jamás admitir la propia responsabilidad en la edificación de un orden totalitario. En su análisis del estalinismo de 1936, Trotski afirmó que la Unión Soviética se había convertido en una sociedad dual: socialista con respecto a la propiedad de los medios de producción, pero "burguesa" en relación con los odiosos mecanismos de control y coerción. Lo "burgués" seguía encar-

${ }^{9} I b i d ., p p .204-205,208-226$. En igual sentido, véase Nikolai I. Bujarín, Ökonomik der Transformationsperiode, 1970, Reinbek, Rowohlt, pp. 110, 116-117, 127, 155-156. Bujarín, que entonces era uno de los dirigentes de la fracción de izquierda, escribió que la nueva disciplina militar hubiera sido en circunstancias capitalistas una especie de esclavismo, pero en un régimen socialista se convertía casi automáticamente en la "autoorganización de la clase proletaria". La libertad de elegir sin coerciones el puesto laboral conformaría una reliquia del individualismo, la insolidaridad y la desorganización del capitalismo, y su supresión sería una conquista socialista (ibid., p. 156). Sobre Bujarín, véase la bibliografía en ibid., pp. 192-195; Sydney Heitman, "Zwischen Lenin und Stalin: Nikolai I. Bujarin", en Labedz, op. cit., pp. 96-114. nando lo negativo, mientras que lo "socialista" — contra toda la experiencia fáctica - continuaba representando únicamente aspectos positivos. La concepción de que la Unión Soviética era un Estado socialista con "degeneraciones burocráticas", pero socialista al fin y al cabo, no ayudó ni a iluminar el pasado ni a establecer un marxismo genuinamente crítico, y más bien contribuyó a seguir arrastrando y exaltando un legado pleno de errores y monstruosidades. ${ }^{10}$

Por lo demás, Trotski y su adversario Bujarín impidieron el surgimiento de un pensamiento genuinamente crítico al repetir hasta el cansancio los lugares comunes de su entorno: para superar el periodo de transición al comunismo pleno había que restablecer las jerarquías y los castigos e instaurar una especie de dictadura pedagógica, ${ }^{11}$ en la que la disciplina laboral resultaba indispensable. Las libertades laborales de los obreros en Occidente serían la manifestación de una crisis incurable. El mercado libe reflejaría la irremediable anarquía del orden burgués y la polarización de clases en los países capitalistas avanzaría sin cesar. La dictadura pedagó-

\footnotetext{
${ }^{10}$ Trotski, Verratene Revolution, 1968, Fráncfort, Neue Kritik, p. 56-58.

${ }^{11}$ Trotski, Terrorisme, pp. 290-291; Bujarín, op. cit., pp. 9, 30-55, 114, 130; interesantes testimonios en A. G. Löwy, Die Weltgeschichte ist das Weltgericht. Bujarin: Vision des Kommunismus, 1969, Viena, Europa, p. 154.
} 
gica se aviene con la visión tecnocrática que tenía la cúpula bolchevique sobre el funcionamiento de la sociedad: es imprescindible sostener una élite de militares, políticos y gerentes, porque la masa de los simples trabajadores no se percata de los complejos problemas asociados a los procesos productivos y administrativos de un Estado moderno.

La diferencia decisiva entre capitalismo y socialismo era vista por Trotski según el "lenguaje de las cifras", en el que los éxitos de producción y productividad y otros factores cuantitativos determinarían cuál es el orden superior. En una de sus últimas obras (La revolución traicionada), que denota cierto espíritu escéptico, Trotski aseveró que el socialismo no ganó su "derecho al triunfo" en las páginas de El capital de Marx, sino en un enorme territorio geográfico y por medio del "idioma del hierro, del cemento y de la electricidad". ${ }^{12}$ De esta manera, las metas normativas establecidas por la modernidad capitalista permanecieron vigentes en el imaginario comunista de todas las corrientes. Bujarín y el

${ }^{12}$ Trotski, Verratene Revolution, p. 12. El mismo tenor posee una obra anterior de Trotski, cuando aún tenía plena confianza en el modelo soviético y no se había percatado de sus "degeneraciones burocráticas": Kapitalismus oder Sozialismus? Eine Betrachtung der Sowjetwirtschaft und ihrer Entwicklungstendenzen, 1925, Berlín, Neuer Deutscher Verlag, pp. 20, 58. destacado economista Evgeni A. Preobrazhenski (1886-1937) —ambos pertenecían entonces a la fracción de izquierda — pensaban en 1919 que el mundo y las sociedades humanas no ofrecerían resistencia seria a un cambio revolucionario inducido por aquellos que conocen el rumbo de la historia y sus necesidades. Lo razonable sería un desarrollo basado esencialmente en el despliegue impetuoso de la técnica y en enormes proyectos de industrialización e infraestructura. Esta "alianza entre la ciencia ${ }^{13} \mathrm{y}$ la industria" estaría inextricablemente ligada a la pronta desaparición del dinero, el Estado, la burocracia y la administración de justicia: una utopía, en la cual también creyeron Marx y Engels.

Lenin, Stalin, Trotski y Bujarín, como casi todos los marxistas rusos, sostuvieron durante largo tiempo que las decisiones del partido comunista eran la encarnación de la verdad. Esta no se conocía a través del análisis teórico o el debate libre de puntos controvertidos, sino mediante las determinaciones del comité central. En mayo de 1924, cuando los acontecimientos y su soberbia ya lo habían colocado en la oposición, Trotski afirmó que "no se puede tener razón contra el partido"

${ }^{13}$ Bujarín afirmó que la "ciencia proletaria" es per se superior a toda ciencia burguesa y que por eso los marxistas tendrían el derecho de exigir acatamiento a sus "verdades"; Bujarín, El materialismo histórico, 1933, Madrid, Cenit, p. 12. 
y que el partido siempre la tiene porque es "el único instrumento que la historia concedió al proletariado para resolver sus problemas". ${ }^{14}$ De acuerdo con casi todos los líderes comunistas, no se podía tener razón fuera del partido. El éxito posterior del estalinismo quedó garantizado desde el primer momento porque hasta sus adversarios más lúcidos creían que el partido personificaba una verdad histórica superior y una forma de organización política más perfecta que todas las inútiles construcciones de la democracia formal y burguesa. No hay duda de que la cultura política del autoritarismo de la Rusia presocialista y la idea de la verdad histórica incorporada en la rígida estructura del partido favorecieron el surgimiento y la consolidación de la dictadura estalinista. ${ }^{15}$ No es superfluo recordar que Lenin mismo contribuyó a este resultado mediante su estricto control sobre toda actividad del partido bolchevique y su rechazo explícito a toda libertad de expresión y crítica internas. De hecho, Lenin calificó tempranamente esa libertad como oportunismo, eclecticismo y oscurantismo. ${ }^{16}$

${ }^{14}$ Trotski, "Discurso ante el XIII Congreso del PCR (B)", en Kostas Papaioannou, Marx et les marxistes, 1972, París, Flammarion, p. 374. Testimonios similares (y escalofriantes) referidos a Bujarín en ibid., p. 380 y Löwy, op. cit., p. 281.

${ }^{15} \mathrm{Cfr}$. la obra clásica de Robert Vincent Daniels, op. cit., pp. 169, 179, 179, 221, 240, 304-311, 318.

${ }^{16}$ Lenin, Was tun?, en Werke, 1960, Berlín, Dietz, t. V, pp. 361 ss. Véase el excelente estudio de

\section{La universalidad de la modernización totalitaria}

Es interesante mencionar, así sea de forma muy breve, que mucho antes de la asunción de Stalin al poder supremo las diferentes corrientes de oposición a la ortodoxia leninista (la "Oposición Obrera", los "Centralistas Democráticos", la "Verdad Obrera", las agrupaciones anarcosindicalistas, los rebeldes de Kronstadt, el "Grupo de los 46"), no aportaron ningún elemento que fructificara en un marxismo crítico o promoviese una cultura política genuinamente democrática. Es cierto que estas tendencias personificaron "la consciencia de la revolución", ${ }^{17}$ puesto que intentaron con todo candor transformar los ideales de 1917 en realidad: solidaridad inmediata entre todos los proletarios y revolucionarios, extinción paulatina del Estado y de sus instancias represivas, terminación de medidas coercitivas en lo relativo a la libertad de expresión y asociación, autonomía de las fracciones en el seno del partido, autonomía sindical y rechazo tanto de las degeneraciones burocráticas del gobierno como de la militarización

Kostas Papaioannou, L'idéologie froide. Essai sur le dépérissement du marxisme, 1967, París, Pauvert, pp. 43-44, 61-62.

${ }^{17}$ Así las denominó Robert Vincent Daniels. Sobre estos grupos y su trágico destino, véase Gottfried Mergner (comp.), Die russische Arbeiteropposition. Die Gewerkschaften in der Revolution, 1972, Reinbek, Rowohlt. 
en la esfera laboral. Pero se trataba de una oposición profundamente dividida, incapaz de actuar en la esfera político-institucional, interesada sobre todo en restaurar la libertad de acción del movimiento sindical y la validez de algunos derechos humanos pisoteados por el gobierno bolchevique. Eran grupos políticos inmersos completamente en la tradición histórica y cultural del autoritarismo. ${ }^{18} \mathrm{Al}$ igual que sus oponentes, rehusaban con la misma vehemencia el pluralismo ideológico, la democracia "formal", las prácticas liberales y la economía de mercado. No se interesaron por la esfera teórica, aunque hay que reconocer que reavivaron un impulso loable por establecer la conexión entre política y ética, de la que procede la fuerte dimensión moral de la oposición soviética después de la Segunda Guerra Mundial.

Las principales demandas de la oposición rusa alrededor de 1920-1924 consistían en: 1) la industrialización masiva, 2) la colectivización de la agricultura, y 3) la planificación exhaus-

${ }^{18}$ Por ello fue extraordinariamente fácil establecer un aparato burocratizado y bastante eficiente, la policía secreta, encargada de combatir a enemigos políticos reales e imaginarios. En torno a este objetivo se puede constatar una sintomática unanimidad entre Lenin y Stalin, Bujarín y Trotski, la oposición de izquierda y las fracciones de derecha. Solo hubo alguna controversia acerca de la aplicación de métodos y a la intensidad de las medidas represivas. Véase Borys Lewytzkyj, Die rote Inquisition. Die Geschichte der sowjetischen Sicherheitsdienste, 1967, Fráncfort, Societät. tiva, lo que imponía por necesidad la abolición del mercado y de los productores independientes. Más tarde la ortodoxia estalinista hizo suyas estas demandas. En el plano de la teoría, esto significó la falta de una consciencia crítica frente a los intentos de la modernización totalitaria estatista, que, después de todo, fue la constante en Rusia a partir del zar Pedro el Grande: a nadie le sorprendió la mixtura de la tecnología occidental y el legado de la cultura política del autoritarismo. La adopción de elementos centrales del capitalismo alemán de guerra se combinó inextricablemente con el viejo mesianismo ruso y con formas secularizadas del milenarismo popular de aquellas tierras: la europeización de Rusia en el campo técnico-económico se conjugó con un retorno a modelos asiáticos de despotismo tradicional. ${ }^{19}$ El gran logro de la Rusia comunista fue la creación de un modelo estable (duró setenta años) que aunaba una

${ }^{19}$ Véase sobre este punto, Emanuel Sarkysianz, Russland und der Messianismus des Orients, 1955, Tubinga, Mohr-Siebeck, pp. 7, 138, 168; Richard Pipes, Russland vor der Revolution. Staat und Gesellschaft im Zarenreich, 1984, Múnich, DTV, passim; Umberto Melotti, Marx y el tercer mundo. Contribución a un esquema multilineal de la concepción del desarrollo histórico elaborada por Marx, 1974, Buenos Aires, Amorrortu, pp. 122-125, 138-151. En todas las variantes del marxismo crítico faltó una obra como estas, que interpretan hasta qué grado el socialismo existente preservó necesaria y conscientemente las tradiciones autoritarias y totalitarias de la época presocialista. 
modernización burocrática, decretada desde arriba y copiada de modelos foráneos, con una herencia sociocultural caracterizada por la falta de elementos racionales, humanistas, liberales y democráticos. Precisamente el hecho de que nadie analizó teóricamente esta constelación y extrajo las consecuencias éticas y políticas es uno de los factores para aseverar que nunca hubo un marxismo genuinamente crítico en la antigua Unión Soviética.

A partir de 1917 en Rusia y después de 1945 en Europa Oriental y en el Tercer Mundo, ortodoxos y disidentes del marxismo aceptaron como obvio e inevitable un modelo de desarrollo que era, en el fondo, un sistema autoritario, cuando no totalitario, de modernización, que mediante los conocidos procesos de la industrialización acelerada, la acumulación forzada de capital, la explotación inhumana de los productores independientes y los campesinos, la educación especializada y hasta las manipulaciones poblacionales (traslados coercitivos de enormes poblaciones de diversas etnias de una zona a otra), trató de alcanzar y superar la evolución de las naciones occidentales en un tiempo muy breve. En 1924, Evgeni A. Preobrazhenski, quien siempre perteneció a la oposición izquierdista dentro del Partido Comunista de Rusia (B), manifestó en el marco de su teorema de la "acumulación primaria socialista" cínica pero correctamente que los campesinos conformarían "las colonias" del proletariado industrial en explícita alusión al papel que cumplieron las colonias de ultramar en el proceso de la acumulación capitalista primaria. ${ }^{20}$ Ya en 1920 Grigori E. Zinóviev (1883-1936), el gran dirigente de la fracción de izquierda, íntimo colaborador de Lenin y presidente de la Internacional Comunista, había sostenido que las partes asiáticas de la Unión Soviética constituirían una especie de colonias para la Rusia europea. ${ }^{21}$

Lo que faltó a la teoría de los opositores marxistas antiestalinistas fue una reflexión crítica en torno a una problemática central. La transferencia de recursos del sector presocialista (campesino y artesanal) al socialista (industrial y burocrático), es decir, la "acumulación primaria socialista", representa una contradictio in adiecto según la doctrina primigenia

${ }^{20}$ E. A. Preobrazhenski, Die neue Ökonomik, 1971, Berlín, s.e., passim. Sobre esta discusión, véase Alexander Erlich, The Soviet Industrialization Debate 1924-1928, 1967, Cambridge, Harvard University Press.

${ }^{21}$ Zinóviev, "Discours au Soviet de Petrograd du 17. IX. 1920", en Kostas Papaioannou, Marx, p. 345 (para otros testimonios de los más prominentes líderes bolcheviques sobre este tema y con el mismo tenor, véase ibid., pp. 342-349). Lo mismo puede aplicarse a los países satélites de la Unión Soviética después de 1945; cfr. Marc Paillet, Marx contre Marx. La société technobureaucratique, 1971, París, Denoë1/Gonthier, p. 151. 
de Karl Marx. La contaminación del "reino de la libertad" con los elementos alienantes y despóticos de regímenes presocialistas hace imposible la crítica y el distanciamiento con respecto a estos instrumentos y procesos, los disimula como algo ineludible (y relativamente inocuo) y los perpetúa como fenómenos obvios y "naturales" inherentes a todo orden socialista. El sometimiento de toda la población mediante el uso amplio de procedimientos represivos revigoriza las tradiciones más autoritarias del pasado. El capitalismo alemán de guerra representó para Lenin, como se sabe, un dechado de virtudes digno de ser imitado en la Rusia soviética. Todos los trabajadores deberían agruparse en un solo organismo económico que funcionaría con la precisión de un reloj y que tendría que obedecer la voluntad de un único dirigente. Todos los obreros deberían ser empleados del Estado; el socialismo no sería otra cosa que un monopolio del capitalismo de Estado utilizado para el provecho de todo el pueblo. ${ }^{22}$ Lenin propugnó la utili-

${ }^{22}$ Lenin, "Ursprünglicher Entwurf des Aufsatzes 'Die nächsten Aufgaben der Sowjetmacht”', en Günther Hillmann (comp.), Für und wider die Bürokratie. Schriften und Briefe 1917-1923, 1970, Reinbek, Rowohlt, pp. 24, 49. Para críticas a esta posición, véase Daniels, op. cit., pp. 83-86, 108, 460; Papaioannou, L'idéologie, p. 52; Ulf Wolter, Grundlagen des Stalinismus. Die Entwicklung des Marxismus von einer Wissenchaft zur Ideologie, 1975, Berlín, Rotbuch, pp. 83-94, 126. zación de los medios más represivos para alcanzar sus fines: aconsejó no arredrarse ante los "procedimientos bárbaros" de Pedro el Grande para luchar contra la "barbarie", ${ }^{23}$ que era, en realidad, lo premoderno. Esta posición, que privilegia la centralización, los métodos militares y la burocracia como los mecanismos más eficientes de organización social, ha sido inmensamente popular en todos los partidos comunistas y en círculos de marxistas de toda laya. $\mathrm{Su}$ inconveniente estriba en que se halla contrapuesta a las características que Marx atribuyó a un régimen socialista: el acercamiento efectivo al "reino de la libertad", la terminación de los fenómenos de alienación y enajenación, la paulatina extinción del Estado, el libre desenvolvimiento del individuo eximido de las coerciones sociales.

Todos estos elementos facilitaron el advenimiento del estalinismo, sobre todo si este régimen trajo el renacimiento de prácticas y valores asociados a lo que se ha llamado el asiatismo. La construcción del socialismo en el seno de una sociedad que no estaba preparada para ello ${ }^{24}$ ha

${ }^{23}$ Lenin, Werke, t. 27, p. 333; para otros testimonios similares de Lenin, véase Papaioannou, Marx, p. 314.

${ }^{24}$ Se encuentran testimonios de Marx y Engels sobre lo que sucedería si tiene lugar un intento prematuro de construir el socialismo en un medio que económica y culturalmente no está preparado 
tenido también una relevancia considerable en la esfera de la teoría: no solo no se promovió ningún impulso realmente crítico, sino que el Estado usó todos los medios a su alcance para transformar el marxismo en un instrumento legitimador del poder. Uno de los resultados de este proceso fue el continuado descenso del nivel teórico: en la obra de Lenin el ímpetu crítico y los elementos heurísticos son ya muy limitados si se los compara con aquellos de los padres fundadores del marxismo, y bajaron aún más hasta tocar fondo con José Stalin (1879-1953), sus secuaces y cortesanos. ${ }^{25}$ De todas maneras, los escritos de Stalin son muy interesantes para comprender las motivaciones, las metas y los intereses profanos de una buena parte de los marxistas hasta entrada la década de $1960 .{ }^{26}$ En ellos aparecen temas del marxismo insti-

para ello en Maximilien Rubel (comp.), Die russische Kommune. Kritik eines Mythos, 1972, Múnich, Hanser, pp. 278-281, 319-325.

${ }^{25}$ Andrej A. Zdanov (1896-1948), alto funcionario del partido y papa de la cultura soviética hasta su muerte, tuvo el mérito de haber aventajado holgadamente a Stalin en la producción de necedades. Por otra parte, no faltaron preclaros espíritus de Occidente que cantaron loas a Stalin de la manera más indigna, como Henri Barbusse, Pablo Neruda y Paul Éluard. $C f r$ r los testimonios similares de Louis Aragon y otros representantes de la cultura francesa en Papaioannou, Marx, pp. 414-417.

${ }^{26}$ Véanse dos buenas selecciones de las obras de Stalin, con interesantes prólogos de los compiladores: Zu den Fragen des Leninismus, 1970, tucional con toda claridad: el ensalzamiento del colectivismo y el vituperio del individualismo; la creación teórica como fabricación de contestaciones simples y fácilmente comprensibles a cuestiones predefinidas de tal modo que es posible una sola respuesta; exégesis de citas clásicas en un tedioso estilo de catecismo como principal trabajo intelectual; concepción maniquea del universo y del hombre (lo "correcto" frente a lo "equivocado"); la investigación científica como recuperación y aplicación de verdades ya manifestadas ex cathedra por los clásicos y sus intérpretes autorizados; teoremas y postulados de los padres fundadores considerados como hechos empíricos comprobados; la dialéctica como una doctrina armonicista en la que finalmente se diluyen todas las contradicciones. La transformación del marxismo en un saber legitimador ocurrió en una sociedad necesitada urgentemente de todo tipo de justificaciones. Se requería, por ejemplo, una ideología que confirmara la validez de unas "leyes de hierro" de la evolución histórica para exculpar o encubrir los actos voluntaristas de los grandes dirigentes (que fueron decisivos para la Revolución de Octubre y el establecimiento de un orden técnicamente moderno bajo Stalin). Se precisaba una ideología

Fráncfort, Fischer; y Stalin, Schriften zur Ideologie der Bürokratisierung, 1970, Reinbek, Rowohlt. 
compensatoria para velar la diferencia entre la realidad prosaica de cada día, plena de los más terribles sacrificios, y los postulados emancipatorios del marxismo original.

\section{Conclusiones provisionales}

Una de las principales insuficiencias de casi todas las variantes del marxismo ha sido su capacidad limitada de comprender en forma realista la complejidad del mundo moderno. $\mathrm{Su}$ posición simplista le impidió percibir las múltiples funciones que cumplen los medios generales y generalizables de la modernidad: el dinero y el poder. La identificación de estos elementos con las fuentes centrales de la alienación deja de lado los variados, razonables e imprescindibles papeles que cumplen para hacer caminar las complicadas sociedades actuales. De ahí la ilusión de que la eliminación de la propiedad privada sobre los medios de producción terminaría pronta y definitivamente con la fuente principal de la enajenación, lo que resultó ser falso.

En la misma línea, Marx y casi todos sus discípulos sobrevaloraron las tareas que el Estado debía cumplir en la etapa socialista, una vez superado el modo capitalista de producción. No se imaginaron, sobre todo, que el aparato estatal podría reproducir y hasta magnificar el legado autoritario de muchas tradiciones culturales, creando una administración pública hipertrofiada y burocratizada, junto con una élite política que se apoderó de las prerrogativas más odiosas. $\mathrm{Ni}$ Marx ni los marxistas críticos concibieron la posibilidad de un estrato muy privilegiado a causa de su acceso al poder y de su control sobre la enorme burocracia ( $\sin$ poseer los medios de producción en sentido legal), y, por lo tanto, no se preocuparon por establecer medidas e instituciones que regularan y refrenaran sus dilatadas potestades. Marx, Lenin y hasta los marxistas críticos del presente creyeron que el socialismo y la estatización de los medios de producción traerían consigo "la administración de cosas" en lugar del "gobierno de las personas" (Friedrich Engels), pero no advirtieron que las cosas se administran siempre junto a hombres de carne y hueso y que cualquier administración (y con más razón una inmersa en un mundo complejo) significa el establecimiento de competencias, la creación de jerarquías, la especialización de las funciones y el surgimiento de privilegios. Esta necesaria diferenciación de grupos y estratos no concuerda con el esquema estático y simple que Marx propuso y que sus discípulos conservaron en lo fundamental: en los países 
más desarrollados no llegó a constituirse un proletariado revolucionario, consciente de su situación de clase inmensamente mayoritaria y de su misión histórica y revolucionaria, que tomara a su cargo la emancipación de la sociedad como totalidad. La consciencia de clase de los obreros en el capitalismo occidental resultó ser afín al reformismo socialdemocrático, puesto que sus ilusiones y esperanzas cotidianas no tenían como punto de referencia las nostalgias utópicas y milenaristas de los intelectuales marxistas. La postulada redención del mundo histórico-político se quedó así sin una clase mayoritaria que le sirviera de sustrato material.
Por último, ni las variantes más críticas del marxismo realizaron aportes significativos a los debates de las últimas décadas. La discusión ecológica y demográfica, la investigación de la cultura de masas, las aporías de la civilización industrial, las diferencias entre trabajo, praxis e interacción, las contribuciones del psicoanálisis sociopolítico y los aspectos negativos asociados a toda modernidad, al igualitarismo excesivo y al progreso material incesante quedaron fuera del horizonte teórico del marxismo, que por ello no ha logrado aprehender la complejidad del mundo contemporáneo. 
Se prohíbe su reproducción total o parcial por cualquier medio, incluido electrónico, sin permiso previo y por escrito de los editores. 